\title{
MEDIAÇÃO E APROPRIAÇÃO DA INFORMAÇÃO PÚBLICA FISCAL: EDUCAÇÃO PARA A CIDADANIA
}

\section{LA MEDIACIÓN Y LAAPROPIACIÓN DE INFORMACIÓN PÚBLICA FISCAL: LAEDUCACIÓN PARA LACIUDADANÍA}

Carmem Lúcia Batista*

\section{RESUMO:}

Introdução: A informação pública, apesar de estar diretamente relacionada a diversas etapas da vida dos cidadãos, esbarra na problemática do acesso intelectual, isto é, na dificuldade de sua apropriação simbólica. Essa situação aponta para a necessidade de mediação entre a sociedade e a produção informacional do Estado.

Objetivo: Refletir sobre os processos de mediação e de apropriação social da informação pública fiscal por meio da recepção de um programa de educação fiscal no estado de São Paulo.

Metodologia: Além de pesquisa bibliográfica, foi utilizada a pesquisa participativa, que se efetivou por meio de tutoria de um curso a distância, reuniões e encontros com os atores da pesquisa.

Resultados: No que se refereaos processos dinâmicos de mediação e de apropriação da informação pública fiscal, a falta de credibilidade do produtor da informação, o Estado, prejudicou o processo de mediação e, consequentemente, o de apropriação das educadoras.

Conclusões: A mediação é insuficiente à apropriação, mas também é indispensável nesse processo. O curso de educação fiscal como dispositivo mediador não consegue articular lógicas e interesses contraditórios entre Estado e sociedade.

Palavras-chave: Mediação. Apropriação.Informação Pública. Educação Fiscal. Cidadania.

*Doutora pelo Programa de Pós-Graduação em Ciência da Informação da Escola de Comunicações e Artes (USP). E-mail: carlubatista@gmail.com 


\section{INTRODUÇÃO}

A informação pública, apesar de estar diretamente relacionada a diversas etapas da vida dos cidadãos (BATISTA, 2010) - já que várias das ações realizadas em uma sociedade são pautadas por determinações do Estado -, esbarra, dentre outras questões, na problemática do acesso intelectual, isto é, de sua apropriação simbólica, pois os dispositivos de mediação desenvolvidos pelo Estado (a linguagem, os meios, os circuitos e a forma de publicação da informação pública) não facilitam a compreensão da informação por destinatários situados nas mais diferentes condições de recepção e com expectativas e interesses concretos, não só diversificados, como divergentes e conflitantes. Há, pois, um problema de comunicação e informação entre o Estado e a sociedade que se somam a vários outros problemas fundamentais do mundo contemporâneo.

Diante desse contexto, esta pesquisa tem comoobjetivorefletir sobre os processos de mediação e de apropriação social da informação pública fiscal por meio da recepção de um programa de educação fiscal no estado de São Paulo. A investigação se deu por intermédio de tutoria de um curso a distância, ministrado aumgrupo social envolvido em ações educativas e culturais afirmativas, isto é, comprometidas com o exercício da cidadania.

\section{NOÇÕES DE MEDIAÇÃO, APROPRIAÇÃO, INFORMAÇÃO PÚBLICA E EDUCAÇÃO FISCAL}

\subsection{Mediação}

Para este trabalho, utilizamos as concepções sobre mediação elaboradas por Braescu (2007), Dufrêne e Gellereau (2004), Jeanneret (2005 e 2009), Lamizet (1999), Caune (1995), Davallon (2003), Rasse (2000) e Perrotti, Pieruccini (2007). Esses autores apontam aspectos do conceito de mediação, ou das variadas noções desse conceito que são importantes a esta pesquisa.

Num resumo das concepções apresentadas por esses autores, temos que a mediação faz parte de um processo informativo/comunicativo que visa sanar problemas implícitos a esse processo de produção da informação. Esse processo, que também é educativo, tem como elemento constitutivo uma 
estrutura triangular, num fluxo não linear, em que a intervenção do "terceiro" implica resultados superiores à simples interação entre as duas partes, quais sejam, a produção e a recepção. A mediação se estrutura por meio de representações simbólicas que visam corroborar o processo de significação do sujeito, enfatizando a dinâmica dos fluxos e das articulações, que, por meio de representações, buscam traduzir formas estéreis em fluxos que fazem sentido ao sujeito.

É por intermédio da mediação que o sujeito pode se apropriar dos objetos e dos bens culturais em circulação, num movimento de construção de autonomia no processo de aprendizagem. Num primeiro momento, o sujeito necessita de uma conjunção entre o objeto que necessita ser mediado, 0 dispositivo de mediação e ele próprio; num segundo momento, por meio da disjunção, o sujeito torna-se apto a construir seus significados próprios da cultura e sobre a cultura em que está inserido.

\subsection{Apropriação}

Para discorrer sobre apropriação, foram estudados autores que salientam elementos ou aspectos de conceitos que interessam a este trabalho, a partir do contexto sociocultural: Lalande (1999), Leontiev (1978), Smolka (2000), Vygotsky (2008), Marx (1977), Marx e Engels (1979), Gléonnec (2003), Chartier (1995), Ricoeur (1986) e Serfaty-Garzon (2003); e do contexto tecnológico: Baillette e Kimble (2008), De Vaujany (2005), Massard (2007 e 2009), Fischer (1983), Proulx (2002), Lemos (2001), Mallet (2006), Yahyaoui (2006), e Cuvelier e Caroly (2009).

A partir dos autores estudados, foi possível inferir que no processo de apropriação há um rompimento de relação binária, que cede espaço a uma composição triangular, como também acontece na mediação. A transformação de binário em triangular faz parte de um processo em que a busca de sínteses resulta numa composição dialética, em que o terceiro elemento, a síntese, surge da dicotomia de pares binários, tais como: passado/presente => compreensão, distância/aproximação => deslocamento; dentre outros. 
Assim, apropriação é um processo no qual o sujeito "torna seu" um objeto do mundo, ajustando-o, moldando-o a si, atuando afirmativamente nos processos de negociação com os signos, com a cultura. Nesse processo, 0 objeto, material ou não, sofre um deslocamento espaço-temporal promovido pelo sujeito, que pode alterar ou confirmar o sentido dado pelo seu ambiente de origem, ou seja, pode ressignificar o mundo que lhe chega, a partir de suas percepções, suas expectativas e seus interesses das e pelas atividades. Assim, na apropriação está implicada uma relação dialética, segundo a qual o sujeito, face ao objeto, desenvolve habilidades para construir suas representações do mundo, e por meio dessas construções simbólicas, o objeto adquire significados que expressam e produzem a subjetividade do sujeito. Dizendo de outro modo: ocorre um processo de construção de subjetividade na relação com o objeto e também a produção de objetos a partir da subjetividade do sujeito. Apropriação seria, assim, "produção", "construção", negociação entre sujeito e objeto, sujeito e mundo.

\subsection{Informação pública}

A noção de informação pública utilizada neste texto foi desenvolvida em trabalho anterior, quando foram considerados vários sentidos implícitos no termo público. Assim,

[...] informação pública é um bem público, tangível ou intangível, com forma de expressão gráfica, sonora e/ou iconográfica, que consiste num patrimônio cultural de uso comum da sociedade e de propriedade das entidades/instituições públicas da administração centralizada, das autarquias e das fundações públicas. A informação pública pode ser produzida pela administração pública ou, simplesmente, estar em poder dela, sem o status de sigilo para que esteja disponível ao interesse público/coletivo da sociedade. Quando acessível à sociedade, a informação pública tem o poder de afetar elementos do ambiente, reconfigurando a estrutura social (BATISTA, 2010, p. 40).

Nesse contexto, o termo público se constitui como oposição a privado e a segredo (BATISTA, 2010; 2011) e implica noções mais amplas, associadas não apenas ao Estado, mas também à sociedade, situação que o aproxima da 
concepção de social e tem como elemento determinante o interesse coletivo/público. Assim, informação pública, além de ser a informação produzida pelo Estado, é a informação sobre o Estado, a qual também é de interesse público. Nesse sentido, as informações que organizações não governamentais divulgam sobre o funcionamento do Estado também são públicas, no sentido de interesse público, embora não sejam estatais. Desse modo, a concepção de informação pública utilizada neste trabalho se inscreve no contexto da produção e da recepção da informação do Estado, ou seja, quando a informação produzida pelo Estado é materializada, institucionalizada e operacionalizada na sociedade.

\title{
2.4 Educação fiscal
}

O conceito de educação fiscal que atualmente orienta as políticas púbicas no Brasil para essa área é o formulado pelo Programa Nacional de Educação Fiscal (PNEF):

\begin{abstract}
Educação Fiscal deve ser compreendida como uma abordagem didático-pedagógica capaz de interpretar as vertentes financeiras da arrecadação e dos gastos públicos, estimulando o cidadão a compreender o seu dever de contribuir solidariamente em benefício do conjunto da sociedade e, por outro lado, estar consciente da importância de sua participação no acompanhamento da aplicação dos recursos arrecadados, com justiça, transparência, honestidade e eficiência, minimizando o conflito de relação entre o cidadão contribuinte e o Estado arrecadador.

A Educação Fiscal deve tratar da compreensão do que é o Estado, suas origens, seus propósitos e da importância do controle da sociedade sobre o gasto público, através da participação de cada cidadão, concorrendo para 0 fortalecimento do ambiente democrático (BRASIL, 2008, p. 27).
\end{abstract}

Esse conceito formulado pelo PNEF é norteador do curso Disseminadores de Educação Fiscal, uma formação a distância, elaborada pela Escola de Administração Fazendária (ESAF) em pareceria com os fiscos estaduais a partir das diretrizes do PNEF. 


\section{PROCEDIMENTOS METODOLÓGICOS}

Como metodologia, além de pesquisa bibliográfica, foi utilizada a pesquisa participativa, que se efetivou por meio de tutoria de um curso a distância, reuniões e encontros com os atores da pesquisa. O público-alvo foram aseducadoras do Programa Einstein na Comunidade de Paraisópolis, um programa que atende a uma comunidade da periferia da cidade de São Paulo. Esse programa tem o objetivo declarado de melhorar a qualidade de vida, prevenir doenças e promover a saúde dos moradores da comunidade.

O curso em questão é o Disseminadores de Educação Fiscal (DEF), que foi implantado desde 2004, é resultado da parceria entre órgãos federais, estaduais e municipais em todo o país e é de responsabilidade da ESAF, departamento da Secretaria da Receita Federal. Em São Paulo, o curso é orientado pela Escola Fazendária do Estado de São Paulo (Fazesp) e acompanhado pelo Grupo de Educação Fiscal (GEF). Por essa razão, o curso é disponibilizado pela internet na página da ESAF (www.esaf.gov.br).

A tutoria para as educadoras do Einstein ocorreuno primeiro semestre de 2012 e teve duração de quase três meses. Participaram do curso 13 educadoras, mas apenas 11 o concluíram. Nesse curso foi observado como as educadoras se apropriavam, ou se se apropriavam, da informação pública na área fiscal e, especialmente, como reagiam às propostas do curso.

Inicialmente, o propósito desta pesquisa era, além da tutoria do curso de educação fiscal, a inserção da temática fiscal nas atividades educacionais do Programa Educação Cidadã, que faz parte do Núcleo de Educação do Programa Einstein na Comunidade de Paraisópolis e atende adolescentes entre 11 e 14 anos que participam diariamente de atividades culturais e educacionais do Programa. Pretendia-se, com isso, que fossem abordadas formas efetivas de participação social de Paraisópolis em políticas públicas do estado de São Paulo, e também que a temática fiscal tratada no curso fosse posteriormente trabalhada com os alunos. Contudo, por uma série de razões, explicitadas mais adiante, não foi possível prosseguir com a pesquisa junto aos adolescentes. 


\section{O CURSO DEF E A INTERAÇÃO DAS EDUCADORAS}

O curso DEF é um dispositivo de formação a distância, característica que traz implicações que movimentam aspectos pedagógicos e tecnológicos. Alguns autores, como Paquienséguy (2007), Peraya (2009) e Paquelin (2004 e 2009), tratam como único o dispositivo de formação a distância, pois engloba várias funcionalidades e dimensões (técnica, simbólica e comunicacional). Por essas características, Deschryver, Lameul e Peraya (2011) denominam o dispositivo de "híbrido", pois supõe a utilização de um espaço tecnopedagógico. Também é um espaço em que há que se considerar o poder do tutor/instrutor sobre o destinatário e vice-versa.

Assim, um dispositivo de formação a distância é, sobretudo, um espaço de discurso, de aprendizagem e de mediação, onde práticas pedagógicas podem ser contestadas, apropriadas e avaliadas, numa relação de poder e de negociação de significados.

\subsection{Características do curso}

Em termos de conteúdo, o curso DEF é estruturado por cinco módulos, sendo quatro deles com o conteúdo do curso, organizado por uma sequência de slides. O quinto módulo é voltado para o desenvolvimento de um projeto pedagógico ou um plano de ação. No final de cada módulo de conteúdo, há um fórum para discussão, que deve ocorrer a partir da leitura de um texto. Esses textos são escolhidos pela supervisão do curso, composta por funcionários da ESAF, que de tempos em tempos alteram os textos.

- Módulo I: é apresentado o cenário sociopolítico do Brasil; é valorizada a educação para a autonomia; é apresentada a importância da educação fiscal e do PNFE. Texto: sobre corrupção e ética. Questão do Fórum: sobre como contribuir para uma sociedade mais ética.

- Módulo II: é apresentado um histórico sobre o Estado; são apresentados conceitos de democracia, de cidadania e de desenvolvimento; é abordada a questão da ética. Texto: sobre a importância do Estado. Questão do Fórum: exaltação da desigualdade social, alerta sobre a injustiça fiscal 
(quem tem menor renda paga mais impostos) e questiona o papel do Estado na redução da desigualdade social.

- Módulo III: além da explicitação do sistema tributário nacional, é apresentado um exemplo de como exercer a "cidadania fiscal"; é abordada a questão da igualdade e da justiça. Texto: sobre tributação dos pobres e reivindicação de direitos. Questão do Fórum: sobre como contribuir para mudança de cenário a partir da educação fiscal.

- Módulo IV: são apresentadas formas de controle social do gasto público; retomada do tema educação fiscal e democracia. Texto: sobre responsabilidade e comprometimento. Questão do Fórum: sobre a responsabilidade social de cada um sobre a realidade local e o que fazer para se ter uma postura cidadã.

- Módulo V: elaboração de projeto pedagógico ou plano de aula.

No que se refere à gestão do curso DEF, os recursos tecnológicos da plataforma Moodle permitem a atuação de coordenação e de tutoria das atividades desempenhadas pelos alunos. Ao tutor cabe a tarefa de fazer a mediação do curso. Além das questões de ordem operacional (mediação das comunicações entre alunos e coordenação do curso, encaminhamento de problemas administrativos à ESAF etc.) e as de ordem tecnológica (dificuldade de acesso em razão do navegador utilizado, acesso bloqueado, etc.).

Em se tratando de recursos técnicos, o curso DEF apresenta as seguintes características: percurso de aprendizagem dos recursos (textos, documentos, multimídias, links), atividades e ferramentas integradas na plataforma (fóruns, questionários, enquetes etc.), rastreamento e avaliação dos alunos (estatísticas de conexão, índice de aprovação, entrega de atividades, troca de mensagens via plataforma etc.). Dentre essas possibilidades, destacamos os recursos de mediação entre tutor e alunos e de interação dos alunos entre si: perfil do participante, fórum de apresentação, fórum para interação entre alunos e tutor, fórum de notícias, chat.

Apesar de o curso ser a distância, são previstos encontros presenciais com a turma toda ou com parte dela, caso seja necessário. Essa opção é feita pelos alunos. 


\subsection{Mediações eapropriações no curso DEF}

As interações das educadoras com o curso foram analisadas a partir da participação nos fóruns, da comunicação por e-mail e do encontro presencial, considerando três aspectos: mediação do dispositivo, mediação da tutora, apropriação do conteúdo do curso.

\subsubsection{Mediação do dispositivo}

Antes do início do curso, no primeiro contato feito pela tutora, os alunos foram orientados a completar os dados do Perfil - que já havia sido preenchido com os dados principais de cada aluno pela coordenação do curso -, para incluírem fotos e informações sobre gostos e preferências, e também a se apresentarem no Fórum de Apresentação. No entanto, das 13 educadoras, apenas duas preencheram os dados.

Embora os alunos tivessem sido avisados sobre a possibilidade de abrirem tópicos de discussão no fórum para interação com o tutor, nenhum deles utilizou o recurso. Um tópico para discussão nesse fórum foi utilizado apenas pela tutora, que se interessava em saber dos alunos sobre a experiência de cada um com curso a distância, acesso, navegabilidade, organização das informações etc. Apenas três educadoras do Einstein responderam a questão. Pela amostragem foi possível perceber que, dentre as alunas, havia vários níveis de habilidade com ferramentas de curso a distância.

Em razão dessa heterogeneidade e do tempo que muitas alunas precisavam para conhecer melhor o dispositivo, foi adotado o seguinte procedimento: a cada intervenção da tutora nos fóruns, ela enviaria uma mensagem personalizada ao aluno. Com esse recurso, ao mesmo tempo em que a aluna era alertada de que o post dela foi lido, também eram dadas orientações sobre procedimentos ainda pendentes.

O fórum de notícias tem uma função apenas de divulgação, mesmo com a possibilidade de as alunas poderem responder às mensagens e notícias. Dos sete textos ou notícias postados nesse fórum, apesar de os alunos terem sido 
avisados pela tutora sempre que um novo texto era publicado, nenhum foi comentado.

Em relação ao chat, não houve êxito. Eram disponibilizadas opções de horários em períodos alternados (manhã, tarde e noite), em dias alternados (dias da semana e fim de semana) e ainda a possibilidade de as alunas sugerirem outros horários e dias.

Além de todas essas possibilidades de interação, as alunas e a tutora podiam trocar mensagens via dispositivo, plataforma do curso, e via e-mail pessoal; também era possível o contato telefônico. Dentre todos os recursos disponíveis, esses três foram os mais utilizados.

Esses fatores apontam para uma dificuldade de apropriação dos recursos tecnológicos do dispositivo.Em razão da falta de tempo dos alunos, os recursos interativos da plataforma do curso foram pouco utilizados, como aconteceu com o chat, que não foi um recurso apropriado pelos alunos, não apenas por causa das dificuldades técnicas, mas principalmente porque poucos alunos se interessaram pelo recurso. Assim, somente os recursos obrigatórios (porque faziam parte da avaliação) foram assimilados pelos alunos.

Na tentativa, por parte da tutora, de sanar as duas maiores dificuldades apresentadas pela turma, é possível observar alguns resultados positivos e outros nem tanto. Por um lado, as mensagens personalizadas enviadas a cada aluno os ajudaram a ganhar tempo, a entender mais rapidamente 0 funcionamento do curso, a cumprir prazos.

Por outro lado, houve aspectos negativos. O primeiro deles foi 0 desenvolvimento parcial de competências tecnológicas. O segundo deles foi 0 desenvolvimento parcial da autonomia do aluno. Alguns alunos apresentaram certa dependência dessa "tutela", tanto que perguntavam o que mais precisava ser feito, qual era o próximo passo ou pediam para verificar se a tarefa foi feita corretamente. Enquanto alguns alunos apresentaram certa dependência, outros agiram de maneira autônoma e outros afirmaram que não teriam concluído o curso sem o auxílio pontual da tutora.

Não é possível constatar se a dificuldade de apropriação de um dispositivo tecnológico dificulta ou não o desempenho cognitivo do aluno. 
Contudo, o acompanhamento humano e as mediações presenciais, situação em que expressão oral não é documentada, favoreceriam a aprendizagem do grupo.

\subsubsection{Mediação da tutora}

Uma característica dessa turma foi a falta de tempo para dedicação ao curso. Praticamente todas as alunas alegaram ter dificuldades em encontrar tempo para fazer o curso, pois, além de trabalharem, também estudavam. Esse aspecto também teve que ser considerado nas mediações.

Poucas vezes as alunas respondiam aos e-mails, mesmo as mensagens que necessitavam de resposta do aluno para que alguma ação fosse executada; boa parte das vezes, os e-mails enviados pela tutora não eram lidos, nem mesmo os que eram enviados a cada um, em particular, não para todo o grupo.

Assim, uma dificuldade retroalimentava a outra. Ironicamente, apesar da pluralidade de recursos, a comunicação não fluiu muito bem porque as alunas mal tinham tempo para cumprir as tarefas essenciais do curso. A falta de comunicação de algumas fazia com que gastassem muito tempo com questões que podiam ser mais facilmente resolvidas por telefone, como a questão da dificuldade de acesso à plataforma do curso.

Diante desse cenário, algumas providências foram tomadas: maior tempo de disponibilidade online da tutora; participação ativa da tutora nos fóruns de discussão; comunicação virtual personalizada; contato telefônico; encontro presencial com a tutora.

No curso DEF há a possibilidade de um ou mais encontros presenciais. Os alunos que decidem a necessidade ou não desse contato. Com o grupo de educadoras do Einstein houve dois contatos presenciais durante o curso. $\mathrm{O}$ primeiro foi uma pequena reunião que ocorreu dez dias após o início do curso, ocasião em que nem todas educadoras haviam iniciado suas atividades no curso a distância. Do encontro participaram duas educadoras, a coordenadora do programa e a tutora. A coordenadora e as educadoras pareciam bem apreensivas sobre: os prazos estipulados para o término dos módulos; a falta 
de tempo para se dedicarem ao curso; problemas técnicos com a plataforma do curso; as formas de avaliação (o que era considerado? grau de instrução?, quantidade de acesso?, acesso a todos os recursos...?). Todas as questões foram respondidas e só então conseguiram ficar mais tranquilas. Até esse momento, das 13 educadoras do Einstein que iniciaram o DEF, apenas seis haviam acessado a plataforma. Somente após essa pequena reunião que a maior parte das educadoras começou de fato a participar do curso.

Por meio desse episódio, foi possível perceber que manuais para aluno, regulamentos de curso, mensagens eletrônicas e contatos telefônicos são recursos necessários, mas insuficientes em alguns contextos. As respostas a todas as dúvidas apresentadas nessa reunião já haviam sido veiculadas anteriormente por e-mail a todos os alunos e por telefone a quem havia entrado em contato, além de também constarem no Manual do aluno ou no Regulamento do curso.

O segundo contato ocorreu um mês após o início do curso, quando foi marcado um encontro com toda a equipe de educadoras do Einstein e também a coordenadora do programa. Nesse momento foram sanadas as dúvidas que ainda restavam sobre: o funcionamento da plataforma do curso, critérios de avaliação, funcionamento dos fóruns, etc. O principal aspecto desse encontro foi a possibilidade de a tutora conhecer todo grupo e de o grupo conhecer a tutora. Essa proximidade física melhorou a comunicação a distância e possibilitou que as educadoras mais tímidas tivessem a oportunidade de se expressarem abertamente, situação que não ocorria em ambiente virtual ou via mensagem eletrônica ou contato telefônico.

Nesse encontro presencial ficou acertado que haveria um outro encontro durante o curso apenas para tratar das dificuldades de conteúdo, principalmente dos módulos III e IV, que são mais específicos. No entanto, em razão de outros compromissos, a equipe do Einstein cancelou o encontro.

Assim, foi possível perceber que as maiores dificuldades das educadoras foram a falta de tempo para se dedicarem ao curso e o problema de comunicação. 


\subsubsection{Apropriação do conteúdo do curso}

Dada a complexidade da temática tributária e a escassez de contato, que geralmente se tem, com informações acerca do funcionamento do Estado, a expectativa era de que as educadoras tivessem razoável dificuldade em compreender os conteúdos do curso, principalmente os dos módulos III e IV, que são mais específicos. Outra preocupação era a soma da dificuldade com informática ou a falta de habilidade em curso a distância; o receio era de que essa combinação causasse inibição na participação ou desistência do curso. Entretanto, o resultado da participação das educadoras nos fóruns avaliativos foi enriquecedor.

Os fóruns avaliativos apresentam um texto pertinente ao conteúdo de cada módulo, que deve ser debatido pelos alunos.

O módulo I trata da educação fiscal no contexto social e discorre sobre o cenário atual, a educação, o PNEF, as possibilidades de inserção do PNEF no currículo escolar e a urgência de um ethos mundial. Nesse módulo as educadoras participaram com boa desenvoltura, pois o tema educação lhes era familiar.

Por meio das participações nesse fórum foi possível perceber dois aspectos interessantes:

a) a falta de familiaridade com informações sobre o funcionamento do Estado;

b) a questão do acesso à informação pública é associada ao acesso físico à informação.

A proximidade com o tema, proporcionada pelo curso DEF, implicando atribuição de sentido, ressignificação, apropriação etc., foi possível por meio da mediação, tanto a do dispositivo quanto a da tutora.

O módulo II aborda a questão da relação do Estado com a sociedade e discorre sobre cidadania no Brasil; a estrutura do Estado; a administração pública; o Estado democrático de direito; Estado, economia e desenvolvimento; desigualdades sociais. O conteúdo desse módulo também foi bem recepcionado pelas educadoras. Ele trata de questões vivenciadas por todos, 
principalmente a desigualdade social; em razão disso, houve muitas manifestações pertinentes. Destacaram-se:

a) Críticas ao Estado e aos agentes públicos;

b) Discussões sobre questões como políticas públicas e gasto público;

c) O reconhecimento da importância do papel do Estado;

d) Comentários positivos em relação àspolíticas públicas do Estado;

e) A percepção sobre a importância da participação social;

f) Visão positiva da participação social;

g) O reconhecimento da falta de cultura democrática no Brasil, situação que dificulta o bom funcionamento do Estado.

Nesse módulo, a apropriação do conteúdo foi evidente. As questões sociais e educacionais são de fácil entendimento para as educadoras. $O$ próximo módulo não lhes foi tão fácil assim.

O módulo III trata da função social dos tributos, e são abordados os temas: serviços públicos; tipos de tributos; princípios do Direito Tributário; obrigação tributária; distribuição de impostos; documentos fiscais; sonegação de impostos. A descoberta de alguns aspectos tributários discutidos nesse módulo causou muitas reações negativas nas educadoras, pois se deram conta de que a carga tributária brasileira é bem maior do que imaginavam. Dentre as interações das educadoras, destacam-se:

a) Indignação com a realidade tributária nacional, após a tomada de consciência sobre o sistema tributário;

b) Atribuição de responsabilidade pela falta de conhecimento sobre 0 assunto à própria população;

c) Sugestão sobre a necessidade de inserção do tema no currículo escolar;

d) Associação do tema à questão do acesso à informação pública.

É possível observar que a maioria das educadoras tinha pouco conhecimento, ou nenhum, a respeito do sistema tributário brasileiro. O que há em comum em quase todas as participações é a consciência da necessidade de a população aprender mais sobre o funcionamento do Estado, de modo geral, e do sistema tributário, de modo específico. 
O conteúdo do módulo IV é o seguinte: orçamento público; princípios orçamentários; contas públicas; receitas públicas; despesas públicas; gestão financeira; lei de responsabilidade fiscal; execução orçamentária; e orçamento participativo.

Esses temas, todavia, não causaram tanto impacto entre as educadoras quanto os do terceiro módulo. Os destaques na participação das educadoras são:

a) Consideração da apropriação dos negócios públicos como uma forma de construção da cidadania;

b) Indignação após tomada de consciência das educadoras sobre questões tributárias e controle de gasto público despertou.

$\mathrm{O}$ módulo $\mathrm{V}$ dispõe sobre elaboração de projeto pedagógico ou plano de aula, que deve ser, preferencialmente, sobre educação fiscal, mas também pode versar sobre ações de cidadania. Nenhuma das educadoras de Paraisópolis fez projeto na área fiscal. As que fizeram projetos, trataram de cidadania, tema que thes era mais familiar.

Foi possível verificar que alguns alunos que não tinham habilidade com informática ou com cursos a distância tiveram maior dificuldade em expor suas ideias nos fóruns, escreviam pouco, muitas vezes repetiam ideias de outros colegas e com pouco aprofundamento. No entanto, outros que haviam manifestado pouca ou nenhuma habilidade com curso a distância se apropriaram facilmente dos recursos.

\subsection{A recepção das educadoras}

Nove meses após o término do curso DEF, a tutora retornou a Paraisópolis para um encontro com as educadoras do Programa Einstein a fim de verificar o aproveitamento que tiveram em relação ao curso: gostaram do curso? Aplicaram conceitos aprendidos durante o curso DEF nas atividades com os adolescentes?

No encontro estavam presentes onze das treze educadoras que participaram do curso DEF, inclusive as duas que não concluíram o curso; duas das educadoras que fizeram o curso haviam se desligado do Programa 
Einstein. Também estavam presentes a coordenadora do Programa e outras duas educadoras que foram contratadas após o término do curso.

Houve afirmação unânime de que não haviam aplicado nada do conteúdo visto no curso nos trabalhos com os adolescentes do Programa de Educação Cidadã. Além dessa afirmação, as principais observações que fizeram sobre o curso foram:

a) os dois primeiros módulos são fáceis e interessantes; os dois últimos, muito difíceis;

b) dificuldade com curso online;

c) dificuldade de tempo para realizar o curso;

d) não gostaram do curso;

e) o conteúdo do curso DEF é importante;

f) não é possível aplicar o conteúdo dos dois últimos módulos com os adolescentes do Programa de Educação Cidadã;

g) para os adolescentes do Programa de Educação Cidadã são mais importantes outros conteúdos antes de aprenderem sobre educação fiscal.

Esses apontamentos das educadoras incitaram algumas conjecturas:

a) A avaliação formalizada, feita no contexto do curso, mas no final dele, não expressa a percepção real que as educadoras manifestaram nove meses após o término do curso;

b) Será que somente os já iniciados na temática fiscal conseguem estabelecer relações entre o conteúdo do curso e as práticas cotidianas?

c) Para um lugar como Paraisópolis, comunidade com tantas carências, é provável que a educação fiscal só faça sentido na medida que auxiliar a comunidade a resolver seus problemas sociais locais;

d) Será mesmo necessário que se resolvam questões "mais essenciais", como educação, segurança pública e saneamento básico antes da busca pela compreensão da temática fiscal?

Após essa reunião com as educadoras, e as reflexões que foram incitadas desde então, foi necessário reconsiderar os propósitos iniciais da pesquisa (inserir a temática fiscal no Programa Educação Cidadã) e analisar um pouco mais minuciosamente o contexto histórico da educação fiscal anterior ao curso DEF, os atores envolvidos em sua criação, as representações 
e os significados envolvidos na oferta de educação fiscal, etc., comparando com o histórico de Paraisópolis.

\section{O CONFLITO DE LÓGICAS}

Após a análise histórica citada no tópico anterior, foi possível fazer algumas inferências.

A trajetória do desenvolvimento de Paraisópolis foi marcada por situações de conflito com o Estado e com a elite econômica da região. Curiosamente a intensificação da ocupação irregular de Paraisópolis ocorreu nos anos 1960, mesma década em que foi lançado o primeiro programa de educação fiscal em São Paulo, oTalão da Fortuna, no bojo do qual o então governador, Adhemar de Barros, já afirmava: "Cada nota de compra expedida significa sempre mais escolas, mais estradas, mais obras públicas, mais assistência à lavoura, mais progresso." (GOVERNADOR, 1964, p. 1).

De lá para cá, Paraisópolis foi se desenvolvendo, na medida do possível, ao passo que os programas de educação fiscal foram se proliferando, oferecendo um "kit" e anunciando uma receita: educação fiscal = benefício social. Essa situação nos remete à noção de "fórmula", proposta por KriegPlanque (2009). Segundo a autora, uma fórmula se caracteriza pelo fato de tornar-se uma referência social; ela significa alguma coisa para todos e tem como característica dominante a presença de homogeneidade, de estabilidade ou de univocidade, ou seja, características típicas da assimilação, processo que pretende apagar as diferenças, "fagocitando" o que é diferente para homogeneizá-lo.

Provavelmente, por essa razão houve um descompasso entre a avaliação formalizada do curso realizada pelas educadoras e a percepção que manifestaram durante o encontro com a tutora, nove meses após o curso. Durante a avaliação do curso, elas estavam no contexto, ainda que virtual, do Estado, condição vulnerável para assumir voz dissonante do discurso da educação fiscal. $O$ encontro nove meses após o término do curso foi realizado em Paraisópolis, território delas, longe da relação hierarquizada e autoritária estabelecida pelo Estado. 
Nesse contexto, percebemos uma crise de confiança entre Paraisópolis e o Estado. Sobre essa questão, Lobet-Maris (2009) afirma que a crise de confiança entre o cidadão e a política é resultado da fragmentação de decisões políticas. Essa ruptura testemunha a dificuldade do político em cumprir um papel de "diplomata" entre o espaço global e o contexto local, capaz de, ao mesmo tempo, proteger os interesses locais e correr riscos globais. No mesmo sentido, Sales (2004) considera que não há como eximir as elites econômicas e o governo de sua responsabilidade pelo acirramento da questão social. Como decorrência disso, continua a autora, a falta de confiança no Estado é grande, em razão do "pequeno lastro de corrupção e patrimonialismo que caracteriza o Brasil" (p. 89).

Por outro lado, acreditamos que a reação de resistência à temática fiscal por parte das educadoras está, em parte, relacionada com um fator ausente no curso: a falta de parâmetros para ações efetivas. É provável, também, que a dificuldade esteja na complexidade do sistema tributário nacional e no desinteresse que a temática atrai, gerando uma falta de familiaridade com a questão. Contudo, mesmo que o curso DEF tenha reduzido a questão fiscal à tomada de consciência, não à ação efetiva, as educadoras poderiam trabalhar a temática de modo que fizesse sentido à realidade de Paraisópolis. A ausência de direcionamento do curso poderia apresentar uma oportunidade para desenvolvimento de ações locais que envolvessem a temática fiscal. Embora a tributação pareça um assunto distante e difícil, essas características não deveriam ser suficientes para a falta de interesse pelo assunto, pois violência e falta de saneamento básico também são temas duros, mas têm atenção da comunidade de Paraisópolis. Assim, apesar de a temática parecer distante, pode tornar-se mais próxima se mediada no sentido da apropriação, considerados os sujeitos como cidadãos plenos, cumpridores de deveres, mas, ao mesmo tempo, portadores de direitos.

O curso DEF está fundamentado pelo "cumprimento voluntário das obrigações fiscais pelos contribuintes" enquanto a equipe de Paraisópolis está preocupada com a "afirmação de direitos" por meio do uso justo dos recursos públicos arrecadados. Tanto o programa do Estado quanto o de Paraisópolis são voltados para a educação e para o desenvolvimento da consciência cidadã 
- no caso do Estado há o Programa de Educação Fiscal para a Cidadania, ao qual está inscrito o DEF, e no que concerne a Paraisópolis, as participantes do curso são educadoras do Programa de Educação Cidadã -, no entanto, cada programa defende um aspecto da cidadania: o Estado enfatiza o dever de pagar impostos, o Programa Einstein, a afirmação de direitos.

Desse modo, para serem considerados como "estímulo à cidadania" ou "desenvolvimento de uma consciência cidadã", os programas de educação fiscal necessitariam preparar os sujeitos para a atividade política, para a compreensão da comunidade política e para as situações de exercício de cidadania. Parece-nos insuficiente ou inócuo que esses programas, denominados de "educação fiscal" foquem seus objetivos no combate à sonegação ou no despertar da consciência para o "cumprimento voluntário das obrigações fiscais pelos contribuintes". Se direitos e deveres, caráter ambivalente da cidadania, não forem igualmente contemplados, as práticas que visam o exercício da cidadania tornam-se impróprias ou incompletas.

Da mesma forma, adotar uma postura apenas de resistência e de reivindicação de direitos, não criará espaço para compreensão dos meandros dos negócios públicos, como definição de agenda política. Como os recursos financeiros do Estado advêm, majoritariamente, da arrecadação tributária, a questão fiscal afeta diretamente qualquer política pública, pois é a receita tributária que viabiliza financeiramente as políticas de segurança pública, de saúde, de educação etc. No entanto, apenas a elucidação dessas questões é insuficiente para viabilizar a participação social nos negócios públicos.

\section{CONSIDERAÇÕES FINAIS}

Por meio do curso DEF, o Estado lança mão de um modelo triangular de informação/comunicação, utilizando um dispositivo pedagógico duplamente mediado, pois o dispositivo em si já é um instrumento de mediação e há, também, a figura do tutor, outro mediador. No entanto, apesar de triangular, o modelo não é dinâmico, pois os fluxos informativos/comunicativos são unilaterais e autoritários. Além da necessidade de mediação entre sociedade e Estado, as questões relacionadas à informação do setor público necessitam de um fluxo dialógico que viabilize a negociação de significados entre os atores, 
que necessitam se compreender mutuamente. Porém, como cada um tem seu lugar de fala, sua lógica e seus interesses próprios, a produção de informação pública de ambas as partes necessita ser mediada.

No que tange aos processos dinâmicos de mediação e de apropriação notamos que a falta de credibilidade do produtor da informação, o Estado, prejudicou o processo de mediação e, consequentemente, o de apropriaçãodas educadores de Paraisópolis. A injustiça social, a complexidade do tema simplificada na "fórmula" educação fiscal = benefício social, dentre outros fatores, afetaram o processo de recepção das educadoras. Essa situação também poderia ter afetado as educadoras de outra forma, caso elas tivessem vislumbrado essa deficiência como uma oportunidade para ações propositivas, sobre a temática fiscal, junto à comunidade. Contudo, o histórico de Paraisópolis, de enfrentamento às ações políticas consideradas de exclusão, implica uma posição de resistência às propostas do Estado.

Enfim, vimos, no trabalho com as educadoras de Paraisópolis, que a mediação é insuficiente à apropriação, mas também é indispensável nesse processo, pois sem as mediações do curso, as educadoras poderiam nem ter tomado consciência do contexto fiscal em que vivem. Nesse sentido, podemos concluir que os cursos de educação fiscal como dispositivos mediadores não conseguem articular lógicas e interesses contraditórios.

\section{REFERÊNCIAS}

BAILLETTE, P.; KIMBLE, C.The concept of appropriation as a heuristic for conceptualizing the relationship between technology, people and organisations.In: UKAIS CONFERENCE, 13., 2008, Bournemouth. Proceedings...Bournemouth, 2008.2015 Disponível <http://arxiv.org/ftp/arxiv/papers/0804/0804.2847.pdf>. Acesso em: 10 jul. 2015.

BATISTA, C. L. Informação pública: entre o acesso e a apropriação social. 2010. 202f. Dissertação (Mestrado em Ciência da Informação)-Escola de Comunicações e Artes, Universidade de São Paulo, São Paulo, 2010.

BATISTA, C. L. Informação pública: uma questão de acesso, de direito e de apropriação social. In: ENCONTRO NACIONAL DE PESQUISA EM CIÊNCIA DA INFORMAÇÃO, 12., Brasília, DF, 2011. Anais Eletrônicos..., Brasília, DF, 2011. 
BRAESCU, V.-S. Enseigner ou "êtreenseignant. Quel rôle pour la médiation dans la transposition didactique? In:

Théorie et pratique en

français. Paris:Editions de la Fondation "EcoulSufletutlui", RamnicuValcea, 2007. p. 45-49.

BRASIL. Escola de Administração Fazendária. Educação Fiscal no contexto social. 3. ed. Brasília, DF: Esaf, 2008.(Série Educação Fiscal, Caderno 1).

CAUNE, J. Culture et Communication: convergences théoriques et lieux de médiation.Grenoble: PressesUniversitaires de Grenoble, 1995. (Coll. La communication em plus).

CHARTIER, R. "Cultura popular": revisando um conceito historiográfico. Estudos Históricos, Rio de Janeiro, v. 8, n. 16, p. 179-192, 1995.

CUVELIER, L.; CAROLY, S. Appropriation d'unestratégie opératoire: unenjeuducollectif de travail. Activités, v. 6, n. 2, p. 57-74, oct. 2009.

DAVALLON, J. La médiation: la communication en procès?. Médiations\&Médiateurs, n. 19, 2003.

DE VAUJANY, F. X. De lapertinence d'une réflexion sur le management de l'appropriation des objets et outils de gestion. In: De la conception à l'usage: vers un management de l'appropriation des outils de gestion. Paris: Editions Management e Société, 2005.

DESCHRYVER, N.; LAMEUL, G.; PERAYA, D. Quel cadre de reférence pour l'évaluation de dispositifs de formation hybrides? COLLOQUE DE L'ADMEEEUROPE: EVALUATION ET ENSEIGMENT SUPERIEUr, 23., Paris, 2011. Actes..., $2011 . \quad$ Disponível em: <file://C:/Documents\%20and\%20Settings/Administrador/Meus\%20documentos /Downloads/unige_21668_attachment01.pdf>. Acessoem 19 abr. 2015.

DUFRÊNE, B.; GELLEREAU, M. La médiation cuturelle: enjeux professionnels et politiques. Hermès: Cognition, Communication, Politique, n. 38, p. 199-206, 2004.

GLÉONNEC, M. Communication et changement organisationnel: le concept de chaîne d'appropriation. In: COLLOQUE BILATÉRAL FRANCO-ROUMAIN, 10.,Bucarest, 2003. Actes..., Bucarest, 2003. Disponível em: <http://hal.inria.fr/docs/00/06/23/66/PDF/sic_00000575.pdf>. Acesso em: 09 jul. 2015.

GOVERNADOR preside o Primeiro Sorteio do "Talão da Fortuna". Diário Oficial do Estado de São Paulo, São Paulo,20 nov. 1964. PoderExecutivo, p. 1.

JEANNERET, Y. La relation entre médiation e usage dans les recherché en information-communication en France. RECIIS, Rio de Janeiro, v.3, n.3, p. 8189, set. 2009. 
JEANNERET, Y. La société de l'information: glossaire critique. Paris: La Documentation Française, 2005.

KRIEG-PLANQUE, A. La notion de "formule » enanalyse de discours. Besançon: Presses universitaires de Franche-Comté, 2009.

LALANDE, A. Vocabulário técnico e crítico da Filosofía. São Paulo: Martins Fontes, 1999.

LAMIZET, B. La mediation culturelle. Paris: L'Harmattan, 1999.

LEMOS, A. Apropriação, desvio e despesa na cibercultura. Famecos, Porto Alegre, n. 15, ago. 2001.

LEONTIEV, A. Desenvolvimento do psiquismo. Lisboa: Livros Horizonte, 1978.

LOBET-MARIS, C. La confiancemise à l'èpreuve de la "modern itéradicale". In: LOBET-MARIS, C.; LUCAS, R.; SIX, B. (Dir.). Variations sur la confiance: concepts et enjeux aus ein des théories de la gouvernance. Bruxelles: Peter Lang, 2009. p.11-14.

MALLET, C. Innovation et mesure de l'appropriation des outils de gestion: proposition d'une démarche de construction d'un tableau de bord. In: COLLOQUE "EN ROUTE VERS LISBONNE", 2006. Disponível em: <http://webserver.tudor.lu/cms/lu2020/publishing.nsf/0/B08C6B6257B00520C1 25720D004C38E1/\$file/Mallet.pdf>. Acesso em: 09 jul. 2015.

MARX, K. Economic and Philosophic manuscripts of 1844. Moscow: Progress Publishers, 1977.

MARX, K.; ENGELS, F.A ideologia alemã: feuerbach. 2. ed. São Paulo: Liv. Ed. Ciências Humanas, 1979.

MASSARD, N. Le processus d'appropriation d'um progiciel de gestionintégré par l'utilisateur final: vers une compréhension des facteurs d'influence Menantaux bonnes pratiques attendues. Aix-Marseille 2: Université de La Méditerranée, 2007.

MASSARD, N. Revisiter la notion d'appropriation: pour une application au cas des ERP. In: COLLOQUE AIM, 14., 2009, Marrakesh. Actes..., 2009. Disponível em: <http://www.reimsms.fr/events/aim2009/pdf/Papier\%20116.pdf>. Acesso em: 09 jul. 2015.

PAQUELIN, D. Le tutorat: accompagnement de l'actualisation du dispositif. Distances et Savoirs, v. 3, n. 2, p. 157-182, 2004. 
PAQUELIN, D. Miseen usage de dispositif de formation: processus, fonction set acteurs de la communication tutorale. Lesenjeux de l'informationet de la Communication, 2009. Disponível em: <http://w3.ugrenoble3.fr/les_enjeux/2008-supplement/Paquelin/home.html >. Acesso em: 07 out. 2015.

PAQUIENSÉGUY, F. Commentré fléchir à la formation des usages liés aux technologies de l'information et de la communicatio nnumériques?.Lesenjeux de l'information et de la Communication, 2007. Disponível em: $<$ http://www.cairn.info/revue-les-enjeux-de-l-information-et-de-lacommunication-2007-1-page-63.htm>. Acesso em: 07 out. 2015.

PERAYA, D. Un régard critique sur les concepts de médiatisation et médiation: nouvelles pratiques, nouvelle modélisation. Les enjeux de l'information et de la Communication, 2009. Disponível em: <http://w3.ugrenoble3.fr/les_enjeux/2008-supplement/Peraya/>. Acesso em: 07 out. 2015.

PERROTTI, E.; PIERUCCINI, I. Saberes e fazeres na contemporaneidade. In: LARA, M.; FUJINO, A.; NORONHA, D. P. (Orgs.). Informação e contemporaneidade: perspectivas. Recife: Néctar, 2007. p. 47-96.

PROULX, S. Trajectoires d'usages des technologies de communication: les formes d'appropriation d'une culture numérique comme enjeu d'une société du savoir. In: Annales des Télécommunications, Paris, t. 57, n. 3-4, p. 180-189, 2002.

RASSE, P. Médiation entre ideal théoriqueet application pratique. Recherche en Communication, n. 13, p. 38-61, 2000.

RICOEUR, P. Du texte à l'action. Paris: Éditions du Seuil, 1986. (Essais d'herméneutique, v. 2).

SALES, M. A. (In)visibilidade perversa: adolescentes infratores como metáfora da violência. 2004. 262 f. Tese (Doutorado em Sociologia) Faculdade de Filosofia, Letras e Ciências Humanas da Universidade de São Paulo. São Paulo, 2004.

SERFATY-GARZON, P. Dictionnaire critique de l'habitation et dulogement. Paris: Armand Colin, 2003, p. 27-30. Disponível em: $<$ http://www.perlaserfaty.net/images/Appropriation\%20-

$\% 20$ un\%20texte\%20de\%20Perla\%20Serfaty-Garzon.PDF>. Acesso em: 29 abr. 2015.

SMOLKA, A. L. B. O (im)próprio e o (im)pertinente na apropriação das práticas sociais. Cadernos Cedes, v. 20, n. 50, p. 26-40, abr. 2000.

VYGOTSKY, L. S. Pensamento e linguagem. 4. ed. São Paulo: Martins Fontes, 2008. 
YAHYAOUI, Y. Innovation et processus d'appropriation sociale de la technologie. In: COLLOQUE INTERNACIONAL "POLITIQUES PUBLIQUES ET INNOVATION SOCIALE DANS LES PAYS DU MAGHREB". 2006, Rabat. Actes..., 2006, Rabat. Disponível em: <www.elyahyaoui.org/harakat_rema_23_24_07.doc>. Acesso em: 09 jul. 2015.

\title{
Title
}

Mediation and appropriation of tax public information: education for citizenship

\begin{abstract}
Introduction: Public information, despite being directly related to different stages of life of citizens, comes up against the problem of intellectual access, that is, the difficulty of its symbolic appropriation. This situation points to the need for mediation between society and the state informational production.

Objective: To reflect on the processes of mediation and social appropriation of tax public information through the receipt of a tax education program in the state of São Paulo.

Methodology: In addition to literature, participatory research was used, which was accomplished through tutoring of a virtual learning course and meetings with actors of the research.

Results: With regard to the dynamic processes of mediation and appropriation of tax public information, the lack of credibility of the producer of the information, the state, undermined the mediation process and consequently the ownership of educators.

Conclusions: Mediation is insufficient to appropriation, but is also essential in this process. The tax education course as dispositive of mediation do not articulate logical and contradictory interests between State and society.
\end{abstract}

Keywords: Mediation. Appropriation. Public Information. Tax Education. Citizenship.

\section{Titulo}

La mediación y la apropiación de información pública fiscal: la educación para la ciudadanía

\section{Resumen}

Introducción: La información pública, a pesar de estar directamente relacionado conlas diferentes etapas de la vida de losciudadanos, se enfrenta conel problema de acceso intelectual, es decir, ladificultad de suapropiación simbólica. Esta situaciónapunta a lanecesidad de lamediación entre lasociedad y laproducción informativa el Estado.

Objectivo: Reflexionar sobre los procesos de la mediación y la apropiación social de la información pública tributaria a través de larecepción de un programa de educación fiscal enel estado de Sao Paulo. 
Metodología: Además de laliteratura, se utilizó la investigación participativa, que se logra a través de la tutoría de un curso de aprendizaje a distancia, encuentros y reunión es con los actores de la investigación.

Resultados: Con respecto a los procesos dinámicos de la mediación y la apropiación de información pública tributária, la falta de credibilidad del productor de la información, el estado, minaron el proceso de mediación y por lo tanto lapropiedad de los educadores.

Conclusiones: La mediación es insuficiente para laapropiación, sino que también es esencialen este proceso. El curso de educación tributaria como dispositivo mediador no articula losintereses lógicos y enconflicto entre el Estado y lasociedad.

Palabras-clave: La Mediación. La Apropiación. Información Pública. Educación Tributária. Ciudadania.

Recebido em: 25.08.2016

Aceito em: 30.11.2016 